\title{
AS PESQUISAS SOBRE A VERTICALIZAÇÃO DAS CIDADES: BREVE HISTÓRICO E DIMENSÕES DE ANÁLISE.
}

\author{
Thiago Augusto Nogueira Queiroz ${ }^{1}$ \\ Ademir Araújo da Costa ${ }^{2}$
}

\section{Resumo:}

Este artigo tem como objetivo realizar um breve histórico das pesquisas sobre a verticalização das cidades, elencando as dimensões de análise existentes na abordagem dessa temática. Para tal fim, fez-se um levantamento das dissertações e teses existentes sobre o assunto nos bancos de dados da Capes, do Ibict, do CNPq, além da contribuiçãode artigos de autoria de Ramires (1998b) e Tows \& Mendes (2011). Os resultados mostraram três momentos diferentes (década de 1980, década de 1990 e início do século XXI) dos estudos sobre a verticalização das cidades, no que tange a cidade estudada, a área da pós-graduação e a instituição onde foram defendidas as teses e as dissertações. Os resultados também demostraram que há sete dimensões de análise sobre a verticalização das cidades: temporal, espacial, técnica, ambiental, econômica, política e cultural. Por fim, propõe-se a necessidade que os estudos dessa temática foquem na dimensão cultural desse processo para crianças e adolescentes.

Palavras-chave: Pesquisas, verticalização das cidades, breve histórico, dimensões de análise.

\section{THE RESEARCH ABOUT THE VERTICALIZATION OF CITIES: BRIEF HISTORY AND DIMENSIONS OF ANALYSIS}

\begin{abstract}
:
This article aims to make a brief history of the research about the verticalization of cities, listing the dimensions of analysis in the approach to this theme. To that end, it was made a survey of the dissertations and theses on the subject in the databases of Capes, Ibict, CNPq, and the articles by Ramires (1998b) and Tows \& Mendes (2011). The results showed three different moments (1980s, 1990s and the beginning of the 21st century) of the studies on the verticalization of cities, with regard to the city studied, the postgraduate area and the institution where the theses were defended and The dissertations. The results also showed that there are seven dimensions of analysis about the verticalization of cities: temporal, spatial, technical, environmental, economic, political and cultural. Finally, we propose the need for studies of this theme to focus in cultural dimension these process to children and teens.
\end{abstract}

Keywords: Researches, verticalization of cities, brief history, analysis dimensions.

\footnotetext{
${ }^{1}$ Doutorando em Geografia pelo Programa de Pós-Graduação e Pesquisa em Geografia da UFRN. E-mail: queiroztan@gmail.com.

${ }^{2}$ Professor Titular em Geografia Humana da UFRN e docente permanente do Programa de Pós-Graduação e Pesquisa em Geografia da UFRN. E-mail: ademir@ufrnet.br.
} 


\section{LA INVESTIGACIÓN SOBRE LA VERTICALIZACIÓN DE CIUDADES: BREVE HISTORIA Y DIMENSIONES DEL ANÁLISIS}

\section{Resumen:}

Este artículo pretende realizar una breve historia de la investigación sobre la verticalización de las ciudades, en la que se enumeran las dimensiones del análisis en el abordaje de este tema. Para ello, se realizó un estudio de las disertaciones y tesis sobre el tema en las bases de datos de Capes, Ibict, CNPq y los artículos de Ramires (1998b) y Tows \& Mendes (2011). Los resultados mostraron tres momentos diferentes (las décadas de 1980 y 1990 y principios del siglo XXI) de los estudios sobre la verticalización de las ciudades, con respecto a la ciudad estudiada, el área de postgrado y la institución donde se defendieron las tesis y las disertaciones. Los resultados también muestran que existen siete dimensiones de análisis sobre la verticalización de las ciudades: temporal, espacial, técnica, ambiental, económica, política y cultural. Finalmente, se propone la necesidad de que los estudios de este tema foque na dimensión cultural dese proceso para hilos e adolescentes.

Palabras claves: Investigación. Verticalización de ciudades. Breve historia. Dimensiones de análisis.

\section{INTRODUÇÃ̃O}

Quando foi proposto para fazer uma tese de doutorado em Geografia sobre a verticalização da cidade de Parnamirim, localizada na Região Metropolitana de Natal, estado do Rio Grande do Norte, duas perguntas vieram à tona: quantos e quais são os estudos existentes, ao longo da história, sobre a verticalização das cidades? Quais são as dimensões de análise desses estudos? Nesse contexto, este artigo tem como objetivo realizar um breve histórico e elencar as dimensões de análise dos estudos sobre a verticalização das cidades, que servirá para a definição dos objetivos e dos fundamentos teórico-metodológicos da tese.

Para tal fim, utilizou-se como procedimento metodológico a pesquisa bibliográfica no Banco de Teses da Coordenação de Aperfeiçoamento de Pessoal de Nível Superior (Capes) e na Biblioteca Digital Brasileira de Teses e Dissertações do Instituto Brasileiro de Informação Ciência e Tecnologia (Ibict). Nesses bancos de dados fez-se a busca pela palavra-chave "verticalização". Complementando e articulando com os resultados dessa busca, utilizou-se os artigos de Ramires (1998b) e de Tows \& Mendes (2011), além da Plataforma Lattes do Conselho Nacional de Desenvolvimento Científico e Tecnológico (CNPq) o Currículo Lattes de alguns professoresque se destacam no desenvolvimento de pesquisas, orientações e participação de bancas de dissertações e teses sobre verticalização. 
Com os estudos levantados foi produzido um quadro com as cinco principais características das dissertações e das teses: ano da publicação; cidade estudada; área de conhecimento; o programa de pós-graduação; e o autor. Excluiu-se do levantamento os artigos publicados em anais de eventos e em periódicos científicos, como também, os livros e capítulos de livros, pois, essas publicações são fragmentos ou a íntegra das dissertações e das teses, portanto, já são contempladas nos bancos de dados.Algumas dissertações e teses significativas podem ter ficado de fora do levantamento devido à desatualização dos bancos de dados existentes. Essa atualização torna-se cada vez mais difícil devido à grande quantidade de novos trabalhos, que é uma consequência positiva da política de expansão dos programas e dos cursos de pós-graduação no Brasil.

Para analisar o quadro construído foi utilizado como procedimento metodológico a análise de conteúdo, no qual destacou-se quais foram os trabalhos pioneiros em relação: à cidade; à tipologia da cidade, se metrópole ou cidade média; ao estado e à região brasileira na qual a cidade estudada está localizada. Também se verificou o pioneirismo em relação: à área do programa de pós-graduação; à instituição do programa de pós-graduação; ao estado e à região brasileira onde se localiza o programa. Por último, identificou-se as temáticas pioneiras de acordo com a dimensão de análise: temporal, espacial, técnica, ambiental, econômica, política e cultural. Todas essas análises foram feitas agrupando e periodizando os trabalhos por décadas.

Este artigo está dividido em três partes. Na primeira parte, discutir-se-á sobre o conceito de verticalização, enquanto um processo típico das cidades brasileiras. Na segunda parte far-se-á um breve histórico dos estudos sobre a verticalização das cidades no Brasil. Na terceira parte do artigo,discutir-se-áas dimensões de análise da verticalização das cidades que vêm sendo utilizadas nas pesquisas sobre verticalização urbana no Brasil.

\section{O PROCESSO DE VERTICALIZAÇÃO DAS CIDADES}

A verticalização é, em uma primeira aproximação, um processo espacial. Os processos espaciais "constituem um movimento de massa, envolvendo uma sequência sistemática e regular de ações em um período de tempo relativamente longo" (CORRÊA, 2007, p.68). A verticalização das cidades é um processo espacial que produz como formas espaciais os edifícios altos e os arranha-céus, que são espaços verticais com funções residenciais ou terciárias (de comércios e serviços). Os edifícios altos são aqueles com mais de quatro 
andares e que se constituem com elevadores (SOUZA, 1994). Os arranha-céus são os edifícios altos com mais de 100 metros de altura (EMPORIS, 2016).

Os edifícios verticais e os arranha-céus passaram a ser construídos, no final do século XIX, nos Estados Unidos, quando foram criadas, pelos engenheiros, arquitetos e urbanistas da Escola de Chicago, as tecnologias do elevador, da estrutura de aço e do concreto armado (MENDES, 2009). Atualmente, o continente com o maior número de arranha-céus no mundo é a Ásia, com $62 \%$ do total mundial. O maior arranha-céu do mundo é o Burj Khalifa, com 828 metros e 160 andares, construído em 2009, na cidade de Dubai, nos Emirados Árabes Unidos (EMPORIS, 2016).

A verticalização das cidades brasileiras teve início na década em 1910 em São PauloSP e na década e 1920 no Rio de Janeiro-RJ (SOUZA, 1994; VAZ, 2002). Na atualidade, essas duas cidades e a cidade de Goiânia-GO são as três cidades com maior número de arranha-céus do Brasil e da América do Sul. Porém, o maior arranha-céu do Brasil está localizado na cidade de Balneário Camboriú-SC, o Millenium Palace, com 177 metros de altura e 46 andares (EMPORIS, 2016).

No estado do Rio Grande do Norte, a verticalização teve início na cidade de Natal-RN, na década de 1930 (COSTA, 2000). Atualmente, a verticalização ocorre de forma intensa nas cidades de Natal e Parnamirim-RN (na Região Metropolitana de Natal), de forma moderada na cidade de Mossoró-RN, e de forma incipiente na cidade de Caicó-RN (COSTA, 2016). Em 2013, foi construído o primeiro edifício em Currais Novos-RN, o Residencial Bella Vista. Na atualidade, o maior arranha-céu do Rio Grande do Norte é o Mirante João Olímpio Filho, com 138 metros de altura e 49 andares, localizado no bairro da Ribeira em Natal (EMPORIS, 2016).

\section{BREVE HISTÓRICO DAS PESQUISAS SOBRE A VERTICALIZAÇÃO DAS CIDADES}

Começa-se o breve histórico dos estudos sobre a verticalização das cidades mostrando o Quadro 1, que contém a listagem de algumas dissertações e teses sobre a verticalização das cidades, do período de 1982 a 2015. Analisar-se-ão os trabalhos pioneiros por década, em termos de: cidades estudadas; programa de pós-graduação onde a dissertação ou tese foi defendida; e sobre a dimensão de análise dos trabalhos. 
Quadro 1 - Listagem de algumas dissertações (D) e teses (T) sobre a verticalização das cidades.

\begin{tabular}{|c|c|c|c|c|}
\hline Ano & Cidade & Pós-Graduação & Instituição & Autor \\
\hline 1982 & São Paulo & História (D) & USP & HOMEM (1982) \\
\hline \multirow[t]{2}{*}{1987} & \multirow{2}{*}{ São Paulo } & Arquitetura (D) & USP & SOMEKH (1987) \\
\hline & & Arquitetura (T) & USP & MACEDO (1987) \\
\hline 1989 & São Paulo & Geografia $(\mathrm{T})$ & USP & SOUZA (1989) \\
\hline 1991 & $\begin{array}{c}\text { Presidente Prudente } \\
\text { Ribeirão Preto } \\
\text { São José do Rio Preto }\end{array}$ & Geografia $(\mathrm{T})$ & USP & SPOSITO (1991) \\
\hline \multirow{2}{*}{1992} & Belém & Geografia $(\mathrm{T})$ & USP & OLIVEIRA (1992) \\
\hline & Maringá & Geografia $(\mathrm{T})$ & USP & MENDES (1992) \\
\hline \multirow{2}{*}{1994} & Rio de Janeiro & Arquitetura (T) & USP & VAZ (1994) \\
\hline & São Paulo & Arquitetura $(\mathrm{T})$ & USP & SOMEKH (1994) \\
\hline 1996 & Manaus & Geografia (D) & USP & MEDEIROS (1996) \\
\hline 1997 & Belo Horizonte & Geografia (D) & UFMG & MACHADO (1997) \\
\hline 1998 & Uberlândia & Geografia $(\mathrm{T})$ & USP & RAMIRES (1998) \\
\hline \multirow{2}{*}{1999} & São Paulo & Administração (D) & FGV & FRANÇA (1999) \\
\hline & São Paulo & Arquitetura (D) & Mackenzie & HOELS (1999) \\
\hline 2000 & Natal & Geografia $(\mathrm{T})$ & UFRJ & COSTA (2000) \\
\hline \multirow{2}{*}{2001} & Curitiba & Geografia (D) & UFPR & TREMARIN (2001) \\
\hline & Maringá & Geografia (D) & UEM & MELO (2001) \\
\hline \multirow{3}{*}{2002} & Guarapuava & Geografia $(\mathrm{T})$ & UFRJ & SILVA (2002) \\
\hline & $\begin{array}{c}\text { Maringá } \\
\text { Cianorte } \\
\text { Umuarama }\end{array}$ & Geografia (D) & UEM & COSTA (2002) \\
\hline & Vitória & Arquitetura $(\mathrm{T})$ & USP & MENDONÇA (2002) \\
\hline \multirow{2}{*}{2003} & Porto Alegre & Arquitetura (D) & UFRGS & KUCHPIL (2003) \\
\hline & São Paulo & Arquitetura (D) & Mackenzie & GARCIA (2003) \\
\hline 2004 & Uberlândia & Geografia (D) & UFU & GOMES (2004) \\
\hline \multirow{2}{*}{2006} & Maringá & Geografia (D) & UEM & TUDINI (2006) \\
\hline & São Paulo & Arquitetura $(\mathrm{T})$ & USP & ALBUQUERQUE (2006) \\
\hline \multirow{9}{*}{2007} & Campinas & Arquitetura (D) & PUC & FERREIRA (2007) \\
\hline & Campinas & Engenharia Civil (D) & Unicamp & DEZAN (2007) \\
\hline & Itapema & Geografia (D) & UFSC & ZEMKE (2007) \\
\hline & Londrina & Arquitetura (D) & Mackenzie & OURA (2007) \\
\hline & Londrina & Geografia (D) & UEL & PASSOS (2007) \\
\hline & Maringá & Geografia (D) & UEM & GIMENEZ (2007) \\
\hline & São Paulo & Arquitetura (D) & Mackenzie & OKANO (2007) \\
\hline & São Paulo & Arquitetura (D) & USP & GALVÃO (2007) \\
\hline & Sorocaba & Geografia (D) & UEM & BARRETO (2007) \\
\hline \multirow{6}{*}{2008} & Aracaju & Arquitetura (D) & Mackenzie & MENEZES (2008) \\
\hline & Recife & Geografia (D) & UFPE & SILVA (2008) \\
\hline & Santos & Sociologia (D) & USP & MELLO (2008) \\
\hline & São Luís & Arquitetura (D) & USP & LEITE (2008) \\
\hline & São Paulo & Arquitetura $(\mathrm{T})$ & USP & KUCHPIL (2008) \\
\hline & Tatuapé & Arquitetura (D) & USP & ENDRIGUE (2008) \\
\hline Ano & Cidade & Pós-Graduação & Instituição & Autor \\
\hline
\end{tabular}

Sociedade e Território - Natal. Vol. 29, N. 1, p. 31 - 49.Jan./Jun. de 2017 


\begin{tabular}{|c|c|c|c|c|}
\hline Ano & Cidade & Pós-Graduação & Instituição & Autor \\
\hline \multirow{3}{*}{2009} & São Paulo & Arquitetura (D) & Mackenzie & BARBOSA (2009) \\
\hline & & & & \\
\hline & São Paulo & Arquitetura (T) & Mackenzie & ZUFFO (2009) \\
\hline \multirow[b]{2}{*}{2010} & Catalão & Geografia (D) & UFG & MARTINS (2010) \\
\hline & $\begin{array}{l}\text { Londrina } \\
\text { Maringá }\end{array}$ & Geografia (D) & UEM & TOWS (2010) \\
\hline \multirow{8}{*}{2011} & Belém & História (D) & UFPA & CHAVES (2011) \\
\hline & Cascavel & Geografia (D) & Unicentro & SANTOS (2011) \\
\hline & Cuiabá & Geografia (D) & UFMT & AFONSO (2011) \\
\hline & João Pessoa & Arquitetura (D) & UFPB & NOBREGA (2011) \\
\hline & Londrina & Geografia (D) & UNESP & SANTOS (2011) \\
\hline & Natal & Geografia (D) & UFRN & PINHEIRO (2011) \\
\hline & Paranaguá & Geografia (T) & UFPR & TONETTI (2011) \\
\hline & São Paulo & Geografia (D) & USP & ZICHELLE (2011) \\
\hline \multirow{6}{*}{2012} & João Pessoa & Arquitetura (D) & UFPB & SILVEIRA (2012) \\
\hline & Maceió & Geografia (D) & UFAL & ALVES (2012) \\
\hline & São Carlos & Engenharia Urbana (D) & UFSCAR & UEDA (2012) \\
\hline & São José dos Campos & Administração (D) & Unitau & NETTO (2012) \\
\hline & São Paulo & Arquitetura (D) & Mackenzie & MICHELIN (2012) \\
\hline & São Paulo & Arquitetura (T) & USP & GALVÃO (2012) \\
\hline \multirow{5}{*}{2013} & Campinas & Engenharia Civil (T) & Unicamp & PEREZ (2013) \\
\hline & Recife & Ciências Geodésicas (D) & UFPE & ARAÚJO (2013) \\
\hline & São Luís & Desenvolvimento (D) & UFMA & SANTOS (2013) \\
\hline & São Paulo & Arquitetura (D) & Mackenzie & GAGLIOTTI (2013) \\
\hline & São Paulo & Arquitetura (D) & USP & ALAS (2013) \\
\hline \multirow{6}{*}{2015} & Francisco Beltrão & Geografia $(\mathrm{T})$ & UFSC & LEME (2014) \\
\hline & Juiz de Fora & Arquitetura (D) & UFJF & CARDOSO (2014) \\
\hline & Londrina & Geografia (D) & UEL & NASCIMENTO (2014) \\
\hline & Porto Alegre & Arquitetura (D) & Mackenzie & BRANDS (2014) \\
\hline & São José dos Campos & Arquitetura (T) & Mackenzie & COSTA (2014) \\
\hline & São Paulo & Geografia (D) & USP & ROCHA (2014) \\
\hline
\end{tabular}

Fontes: Capes (2016); Ibict (2016); CNPq (2016); Tows \& Mendes (2011); Ramires (1998b).

Com base no Quadro 1, observa-se que, na década de 1980, foi publicado o primeiro estudo, uma dissertação, sobre a verticalização das cidades e na área de História (HOMEM, 1982). Nessa mesma década foram publicados os primeiros trabalhos, uma dissertação e uma tese, na área de Arquitetura e Urbanismo (SOMEKH, 1987; MACEDO, 1987); e o primeiro estudo, uma tese, na área de Geografia (SOUZA, 1989). Todas as publicações dessa década foram sobre a verticalização na cidade de São Paulo e todos os trabalhos foram defendidos na Universidade de São Paulo (USP). Esses trabalhos priorizaram as dimensões temporais, espaciais, econômicas e políticas do processo de verticalização. 
Averígua-se, no Quadro 1, que na década de 1990 foi publicado o primeiro estudo, uma tese, sobre a verticalização em cidades médias, a saber: Presidente Prudente (SP), Ribeirão Preto (SP) e São José do Rio Preto (SP) (SPOSITO, 1991). Além disso, foi publicado o primeiro trabalho, uma tese, sobre a verticalização em uma cidade da região Norte do Brasil, a metrópole de Belém (PA) (OLIVEIRA, 1992). Assim como,o primeiro estudo, uma tese, sobre esse fenômeno em uma cidade da região Sul do Brasil, a cidade média de Maringá (PR) (MENDES, 1992).

Nessa década foi publicado inclusivea primeira dissertação defendida fora da USP, na Universidade Federal de Minas Gerais (UFMG); o primeiro trabalho, uma dissertação, na área de Administração; e o primeiro estudo, uma tese, sobre uma cidade da região Nordeste do Brasil, a cidade de Natal (RN), da mesma foram que foi a primeira tese defendida sobre o assunto na Universidade Federal do Rio de Janeiro (UFRJ), ou seja, a primeira tese não defendida na USP (MACHADO, 1997; FRANÇA, 1999; COSTA, 2000).

A primeira tese sobre esse tema, defendida na UFRJ, foi importante para a desconcentração de trabalhos defendidos na USP. Isso mostra também um fortalecimento do Programa de Pós-Graduação em Geografia da UFRJ diante da USP. Tal fato mostra o início da descentralização dos trabalhos sobre essa temática, saindo da Universidade de São Paulo e se propagando para outros estados e posteriormente para outras regiões brasileiras com a expansão dos programas de pós-graduação.

No ano de 1995, o $4^{\circ}$ Simpósio Nacional de Geografia Urbana (Simpurb), realizado em Fortaleza, foi o primeiro evento científico com uma sessão temática sobre verticalização das cidades (RAMIRES, 1998b). Tal fato demonstrou a importância que essa temática adquiriu a partir da década de 1990, juntamente com o crescimento horizontal e vertical das cidades brasileiras. Os trabalhos da década de 1990, assim como os da década anterior, enfatizaram uma abordagem histórica, geográfica, econômica e política do processo de verticalização.

Nesse início do século XXI, conforme mostrado no Quadro 1, foi publicado o primeiro trabalho, uma dissertação, sobre a verticalização em uma cidade da região Centro-Oeste: a cidade média de Catalão (GO) (MARTINS, 2010). No início do século XXI foram publicadosconjuntamente os primeirosestudos em diferentes áreas: Engenharia (DEZAN, 2007); Sociologia (MELLO, 2008); Ciências Geodésicas (ARAÚJO, 2013); e desenvolvimento socioeconômico (SANTOS, 2013). 
Assim como, houve a expansão de defesa de dissertações em programas de pósgraduação de instituições localizadas em outras regiões brasileiras, para além da região Sudeste, a saber: a Universidade Federal do Paraná (UFPR), na região Sul (TREMARIN, 2001); a Universidade Federal de Pernambuco (UFPE), na região Nordeste (SILVA, 2008); a Universidade Federal de Goiás (UFG), na região Centro-Oeste (MARTINS, 2010); e a Universidade Federal do Pará (UFPA), na região Norte (CHAVES, 2011).

Essa expansão das defesas de dissertações para Programas de Pós-Graduação de outras regiões brasileiras, para além do Sudeste, ocorreu devido a política de expansão dos programas de pós-graduação no Brasil, coma criação de novos cursos de metrado acadêmico ou profissional, e de doutorado. O crescimento do número de trabalhos sobre essa temática é consequência da expansão desse processo para um maior número de cidades brasileiras, não só nas metrópoles, assim como, nas denominadas cidades médias.

Em 2006, ocorreu o primeiro evento específico sobre verticalização, intitulado Verticalização - oficina das cidades brasileiras, realizado na Faculdade de Arquitetura e Urbanismo da Universidade Presbiteriana Mackenzie em São Paulo, e coordenadopelo Grupo de Estudos "Verticalização, projetos urbanos e inclusão social". E em 2007, foi realizada uma segunda edição do evento em Porto Alegre (TOWS \& MENDES, 2011). A criação desse evento mostra o quanto cresceu o número de trabalhos sobre verticalização nas cidades brasileiras, assim como esse processo se disseminou pelo país, ao ponto de ter um evento somente para discutir essa temática.

Só na primeira década do século XXI foram publicados 30 trabalhos de teses e dissertações sobre verticalização, ou seja, o dobro dos 15 estudos publicados nos anos anteriores. A partir dessa década começaram a surgir trabalhos voltados para a dimensão cultural do processo de verticalização tal como a tese de Silva (2002) que abordou as representações sociais dos espaços verticalizados de Guarapuava, Paraná.

Na segunda década do século XXI, o número de pesquisas sobre verticalização cresceu de forma exponencial, visto que até a metade da década (2011-2015) já foram publicados 25 trabalhos, que corresponde quase a mesma a quantidade de estudos de toda a década anterior. Nessa atual década começaram a ser publicados os primeiros trabalhos com as dimensões técnicas e ambientais da verticalização, tais como, o de Galvão (2012) sobre a 
reabilitação de edifícios e apartamentos e de Perez (2013) sobre o envelope solar ${ }^{3}$, e de Tonnetti (2011) sobre a qualidade ambiental do adensamento de moradias.

Ao longo dos períodos analisados, já foram escritos 70 trabalhos, 51 dissertações e 19 teses, sobre a verticalização das cidades entre 1982 e 2015. De todas essas pesquisas, 20 são sobre a cidade de São Paulo (SP), seguido de Maringá (PR) e Londrina (PR) com 6 estudos cada uma. Além disso, destacam-se 32 estudos na área de Geografia, seguido de 28 na área de Arquitetura e Urbanismo, sendo as duas áreas onde há mais pesquisas realizadas sobre a verticalização das cidades. Por fim, 22 dissertações ou teses foram defendidas na USP, 11 na Mackenzie, 6 na Universidade Estadual de Maringá (UEM).

A USP se destaca devido ao seu pioneirismo nas décadas de 1980 e 1990 com trabalhos nas áreas de Geografia e de Arquitetura e Urbanismo. A Mackenzie e a UEM destacam-se nessas primeiras décadas do século XXI. A primeira, pela existência do Grupo de Estudos "Verticalização, projetos urbanos e inclusão social", que vem desenvolvendo os trabalhos sobre a verticalização, principalmente, na cidade de São Paulo e na área de Arquitetura e Urbanismo. A segunda, devido aos trabalhos sobre verticalização, especialmente das cidades do Paraná e na área de Geografia, realizados no âmbito do Grupo de Estudos Urbanos (GEUR).

Depois de mostrar um breve histórico dos estudos sobre verticalização das cidades no Brasil, analisar-se-á, na secção a seguir, as dimensões de análise encontradas nos estudos sobre a verticalização das cidades.

\section{DIMENSÕES DE ANÁLISE DAS PESQUISAS SOBRE A VERTICALIZAÇÃO DAS CIDADES}

A partir dos artigos de Ramires (1998b) e de Tows \& Mendes (2011) e da análise das dissertações e teses levantadas no banco de dados da Capes, Ibict e CNPq, definiu-se as dimensões de análise dos estudos sobre a verticalização das cidades: dimensão temporal, dimensão espacial,dimensão técnica, dimensão ambiental,dimensão econômica, dimensão política e dimensão cultural.Todos os trabalhos podem abarcar mais de uma dimensão, porém, destacou-se dos estudos analisados as dimensões preponderantes.

\footnotetext{
3“"Maior volume que uma edificação pode ocupar no terreno de forma a permitir o acesso ao sol e luz natural da vizinhança imediata" (KNOWLES \& BERRY apud PEREZ, 2013, p.8).
} 
A dimensão temporal dos estudos sobre a verticalização das cidades é analisada das seguintes formas: a história da verticalização de uma cidade, desde o início até os tempos atuais, com períodos e fases da verticalização, muitas vezes determinadas por décadas (VAZ, 1994); a verticalização de uma cidade em um determinado recorte temporal ou em uma década anterior (SOMEKH, 1994). Essa dimensão corresponde ao que Ramires (1998b) denominou de etapas (períodos, fases, décadas) da verticalização.

A dimensão espacial dos estudos sobre a verticalização das cidades é abordada da seguinte maneira: a verticalização nas metrópoles; a verticalização nas cidades médias; a verticalização em um bairro; a verticalização em favelas; a comparação da verticalização entre cidades (SOUZA, 1989; MENDES, 1992; ZUFFO, 2009; ALBUQUERQUE, 2006; SPOSITO, 1991). Tal dimensão está associada ao que Ramires (1998) chamou de impactos da verticalização na estrutura interna da cidade; e inclui o que Tows \& Mendes (2011) denominou de estudos comparativos da verticalização.

A dimensão técnica da verticalização ainda é pouca explorada, mas podemos apontar duas formas de abordagens: as técnicas de reabilitação de edifícios e apartamentos; e o uso da técnica do envelope solar para adensamento e verticalização (GALVÃO, 2012; PEREZ, 2013). Essa dimensão corresponde ao que Ramires (1998b) denominou de técnicas de produção da verticalização; e ao que o mesmo autor tratou como as novas tecnologias da verticalização e os prédios inteligentes. Esses trabalhos também poderiam ser categorizados dentro da dimensão ambiental, visto que essas dimensões não se separam.

A dimensão ambiental da verticalização é abordada pelas possibilidades de adensamento de moradias sem agredir a qualidade ambiental da cidade (TONETTI, 2011). O que também não deixa de ser uma dimensão técnica da verticalização. Falta ainda uma abordagem dos impactos ambientais provocados pela verticalização, cobrada anteriormente por Ramires (1998) e por Tows \& Mendes (2011).

A dimensão econômica da verticalização das cidades aparece explorada das seguintes formas nos trabalhos pesquisados: o consumo da habitação enquanto mercadoria dotada de valor, valor de uso e valor de troca; e o mercado imobiliário que envolve a verticalização (RAMIRES, 1998a; LEME, 2015). Essa dimensão econômica inclui o que Ramires (1998b) chamou de incorporação imobiliária e verticalização. Mesmo modo, abrange o que Tows \& Mendes (2011) coloca como o papel do capital enquanto agente da produção do espaço, isto é, como o capital imobiliário atua temporalmente e espacialmente na construção da 
verticalização, e sua relação com os demais capitais (fundiário, industrial, comercial e financeiro), com o Estado e os grupos sociais. Tows \& Mendes (2011) destaca a importância de focar, os estudos dessa dimensão econômica da verticalização, no capital financeiro.

A dimensão política da verticalização das cidades pode ser abordada: de forma direta, sendo o foco principal do trabalho; ou de forma indireta, não sendo a análise principal da pesquisa (SOMEKH, 1987; MACEDO, 1987; OLIVEIRA, 1992; COSTA, 2000; e COSTA, 2015). Todos os trabalhos, direta ou indiretamente, analisam o papel do Estado, o poder público municipal, na legislação urbanística que facilita ou dificulta o processo de adensamento da cidade por meio da verticalização. Este processo de intervenção jurídica do Estado sobre o processo de verticalização é denominado de "desverticalização" por Somekh (1987, 1994).Essa dimensão inclui o que Ramires (1998b) denominou de legislação urbana e verticalização. Outrossim, abrange o que Tows \& Mendes (2011) coloca como o papel do Estado enquanto agente da produção do espaço, ou seja, como o Estado atua temporalmente e espacialmente na organização da verticalização, além de sua relação com o capital (imobiliário) e com os grupos sociais envolvidos. Segundo Tows \& Mendes (2011, p.13) “o Estado é um dos agentes de maior importância contemplado na maioria dos estudos de verticalização".

A dimensão cultural da verticalização pode ser abordada de três maneiras: a mudança do público interessado na moradia em edifícios; o imaginário e imagens da modernidade criado pelo processo de verticalização; e as diferentes representações sociais do processo de verticalização para grupos e sujeitos sociais diversos (MENDONÇA, 2002; KUCHPIL, 2008; SILVA, 2002).Essa última dimensão da verticalização abrange o que Ramires (1998) destacou como a questão da modernidade, juntamente sobre o significado do edifício e da paisagem urbana verticalizada. Mesmo modo, abarca o que Tows \& Mendes (2011) colocaram como o papel dos grupos sociais (especialmente os moradores) enquanto agentes da produção do espaço, isto é, como os grupos sociais atuam temporalmente e espacialmente no uso da verticalização, e a relação deles com o capital imobiliário e com o Estado. Para Tows \& Mendes (2011, p.14) "os estudos ainda carecem de contemplar quem mora nesses edifícios e que público o mercado busca atingir". 


\section{CONSIDERAÇÕES FINAIS}

Pode-se dividir os estudos sobre a verticalização das cidades em três períodos: década de 1980; década de 1990; e início do século XXI. Na década de 1980 os trabalhos se restringiram à verticalização em São Paulo, nas áreas de História, Arquitetura e Urbanismo, e Geografia, sendo todos defendidos na USP. Na década de 1990 os trabalhos passaram a analisar as cidades médias, assim como, cidades das regiões Sul, Norte e Nordeste do Brasil, tendo o primeiro trabalho na área de Administração, e inclusive as primeiras pesquisas defendidas fora da USP.

Desde o início do século XXI, passam a ser publicados trabalhos sobre a verticalização na região Centro-Oeste do Brasil. Além disso, passam a existir dissertações defendidas nas áreas de Engenharia, Sociologia, Ciências Geodésicas e Desenvolvimento Socioeconômico, assim como, estudos defendidos em instituições das regiões Sul, Nordeste, Centro-Oeste e Norte, para além das instituições do Sudeste. Juntando dissertações e teses, só nesse início do século XXI, já foram publicados 55 trabalhos, ou seja, mais de três vezes o número de estudos do século XX (15 dissertações ou teses). Sendo que em 2015, na metade desta década, já se chegou a 25 trabalhos, quase a quantidade de pesquisas realizadas na década anterior (30 dissertações ou teses).

Considerando todos os trabalhos levantados, 51 dissertações e 19 teses, constatamos que a maioria dos estudos foram defendidos na USP (22), na Mackenzie (11) e na UEM (6). A USP destaca-se pelo seu pioneirismo nas décadas de 1980 e 1990, com trabalhos nas áreas de Geografia e Arquitetura e Urbanismo. A Mackenzie tem se destacado neste século XXI com estudos sobre a verticalização na cidade de São Paulo, na área de Arquitetura e Urbanismo. E a UEM, conjuntamente nessas primeiras décadas do século XXI, vem se destacando nas pesquisas sobre a verticalização nas cidades do Paraná, na área de Geografia. Tal fato reflete nas cidades mais contempladas nesses estudos, a saber: São Paulo (20 vezes), Maringá (6) e Londrina (6). Como também, reflete nas áreas de conhecimento com maior destaque: Geografia (32 dissertações ou teses) e Arquitetura e Urbanismo (28).

Por fim, observou-se que as dimensões de análise dos estudos sobre verticalização são: temporal (uma história ou um recorte temporal específico); espacial (uma metrópole, uma cidade média ou um bairro); técnica (desenvolvimento de tecnologias aplicadas na construção dos edifícios); ambiental (mitigação de impactos ou análise dos impactos ambientais); econômica (a atuação do capital na construção dos edifícios); política (a atuação 
do Estado na organização da localização dos edifícios na cidade) e cultural (os significados, os símbolos, as representações da verticalização para os diferentes grupos sociais que utilizam os edifícios).

Verificou-se que a dimensão cultural é a menos explorada e, por isso, as próximas pesquisas relacionadas sobre o processo de verticalização das cidades deveriam enfatizar essa dimensão. Essa dimensão abre a possibilidade de estudos sobre os sentidos da verticalização para cada indivíduo, de diferentes grupos sociais e de diversos contextos espaciais. Assim como, os significados da verticalização para as diversificadas classes sociais de espaços geográficos diferentes. Os simbolismos dessas formas urbanas, o imaginário social sobre elas, e suas representações nas mídias de comunicação e nos discursos das pessoas.

A análise do estado da arte abre uma outra possibilidade para as pesquisas sobre os sentidos, significados e representações dessas formas urbanas verticais para as crianças e os adolescentes. As pesquisas podem verificar qual a influência desses espaços verticalizados, dessa paisagem vertical, na formação da consciência social ou não de crianças e adolescentes que sempre moraram nesses tipos de espaços.Assim como, as contradições da vida cotidiana nos condomínios verticalizados. Os trabalhos que abordam os demais aspectos já se demonstram esgotados e limitados, visto que muitos estudos econômico-políticos, espaçotemporais, técnico-ambientais já foram realizados.

\section{REFERÊNCIAS}

AFONSO, Daniel Correa. Verticalização em Cuiabá/MT: da modernização às problemáticas urbanas atuais. Dissertação (Mestrado em Geografia). Cuiabá: UFMT, 2011.

ALAS, Paulo. O fenômeno dos supercondomínios: verticalização na metrópole paulistana no início do século XXI. Dissertação (Mestrado em Arquitetura e Urbanismo). São Paulo: USP, 2013.

ALBUQUERQUE, Maria José de. Verticalização de favelas em São Paulo: balanço de uma experiência (1989-2004). Tese (Doutorado em Arquitetura e Urbanismo). São Paulo: USP, 2006.

ALVES, Maria Elisa Moreira. O início da verticalização em Maceió-AL: um estudo tipológico dos edifícios multifamiliares em altura (1960-1970). Dissertação (Mestrado em Geografia). Maceió: UFAL, 2012. 
ARAÚJO, Ana Itamara Paz de. Geodésia aplicada aos estudos de verticalização de edifício predial de grande porte. Dissertação (Mestrado em Ciências Geodésicas e Tecnologias da Geoinformação). Recife: UFPE, 2013.

BARBOSA, Eliana Rosa de Queiroz. O BNH e a verticalização em São Paulo: a Cia. Hindi. Dissertação (Mestrado em Arquitetura e Urbanismo). São Paulo: Universidade Presbiteriana Mackenzie, 2009.

BARRETO, Ilson Juliano. A verticalização e o bairro: o caso do Jardim Campolim Sorocaba-SP, no período de 1990-2004. Dissertação (Mestrado em Geografia). Maringá: UEM, 2007.

BRANDS, Juliana Bredow. Edifício Santa Cruz: verticalização e regulação no centro de Porto Alegre. Dissertação (Mestrado em Arquitetura e Urbanismo). São Paulo: Universidade Presbiteriana Mackenzie, 2015.

CARDOSO, Carina Folena. 100 anos de verticalização em Juiz de Fora: edifícios de apartamento na Avenida Barão de Rio Branco. Dissertação (Arquitetura e Urbanismo). Juiz de Fora: UFJF, 2015.

CASARIL, Carlos Cassemiro. Meio século de verticalização urbana em Londrina-PR e sua distribuição espacial: 1950-2000. Dissertação (Mestrado em Geografia). Londrina: UEL, 2009.

CHAVES, Túlio Augusto Pinho de Vasconcelos. Isto não é para nós? Um estudo sobre a verticalização e modernidade em Belém entre as décadas de 1940 e 1950, Dissertação (Mestrado em História). Belém: UFPA, 2011.

CORRÊA, Roberto Lobato. Diferenciação sócio-espacial, escala e práticas espaciais. Cidades, v.4, n.6, p.62-72, 2007.

COSTA, Ademir Araújo. A verticalização e as transformações do espaço urbano de Natal-RN. Tese (Doutorado em Geografia). Rio de Janeiro: UFRJ, 2000.

A reestruturação produtiva e a (re)produção do espaço verticalizado em cidades do Rio Grande do Norte. Revista Formação, edição especial, n.23, v.1, p.112-132, 2016.

COSTA, Luiz Fernando da Silva. Os promotores imobiliários no processo de verticalização das cidades de Maringá, Cianorte e Umuarama. Dissertação (Mestrado em Geografia). Maringá: UEM, 2002.

COSTA, Paulo Eduardo de Oliveira. O processo de verticalização em São José dos Campos. Tese (Doutorado em Arquitetura e Urbanismo). São Paulo: Universidade Presbiteriana Mackenzie, 2015.

DEZAN, Waldir Vilalva. A implantação de uma modernidade: o processo de verticalização da área central de Campinas. Dissertação (Mestrado em Engenharia Civil, Arquitetura e Urbanismo). Campinas: Unicamp, 2007. 
EMPORIS. Buildings - Statisctics - Tallest Buildings / Most Skycrapers. Disponível em: https://www.emporis.com/ .Acesso em: dezembro de 2016.

ENDRIGUE, Taísa da Costa. Tatuapé: a valorização imobiliária e a verticalização residencial no processo de diferenciação sócio-espacial. Dissertação (Mestrado em Arquitetura e Urbanismo). São Paulo: USP, 2008.

FERREIRA, Caio de Souza. O processo de verticalização na cidade de Campinas: da gênese à lei 640 de 1951. Dissertação (Mestrado em Arquitetura e Urbanismo). Campinas: PUC, 2007.

FRANÇA, Cássio Luiz de. Experiências de verticalização de favelas na cidade de São Paulo na década de 1990: análise de impacto na cultura política. Dissertação (Mestrado em Administração Pública e Governo). São Paulo: Fundação Getúlio Vargas, 1999.

GAGLIOTTI, Guilherme. A verticalização em São Paulo, de 1980 a 2011 : concentração e dispersão. Dissertação (Mestrado em Arquitetura e Urbanismo). São Paulo: Universidade Presbiteriana Mackenzie, 2013.

GALVÃO, Walter José Ferreira. Copan/SP: a trajetória de um megaempreendimento, da concepção ao uso. Dissertação (Mestrado em Arquitetura e Urbanismo). São Paulo: USP, 2007.

Roteiro para diagnóstico do potencial para reabilitação de edifícios de apartamentos antigos. Tese (Doutorado em Arquitetura e Urbanismo). São Paulo: USP, 2012.

GARCIA, Isabel Coimbra da Silva. A verticalização da cidade de São Paulo no final do século XX: o caso da vila olímpica. Dissertação (Mestrado em Arquitetura e Urbanismo). São Paulo: Universidade Presbiteriana Mackenzie, 2003.

GIMENEZ, Humberto Marshal Mendes. Interpretação do espaço urbano de Maringá: a lógica da verticalização período de 1990 a 2005. Dissertação (Mestrado em Geografia). Maringá: UEM, 2007.

GOMES, Eduardo Rodrigues. O processo de verticalização litorânea em Vitória (ES): um estudo de caso do bairro Praia do Canto (1970-2000). Dissertação (Mestrado em Geografia). Uberlândia: UFU, 2004.

HOELS, Patrícia Van. A verticalização residencial em São Paulo (1980-1998): o bairro do Morumbi. Dissertação (Mestrado em Arquitetura e Urbanismo). São Paulo: Universidade Presbiteriana Mackenzie, 1999.

HOMEM, Maria Cecília Naclério. A ascensão do imigrante e a verticalização de São Paulo: o prédio Martinelli e sua história. São Paulo: Dissertação (Mestrado em História). São Paulo: USP, 1982. 
KUCHPIL, Eneida. Cidade vertical: morfologia, densidade e qualidade de vida. Dissertação (Mestrado em Arquitetura e Urbanismo). Porto Alegre: UFRGS, 2003.

. O edifício vertical e a cidade: imagens da modernidade sob o olhar do espaço público. Tese (Doutorado em Arquitetura e Urbanismo). São Paulo: USP, 2008.

LEITE, Carolina Gaspar. Alterações da verticalização urbana frente ao processo de verticalização das avenidas litorâneas: o caso da Avenida Litorânea em São Luís, MA. Dissertação (Mestrado em Arquitetura e Urbanismo). São Paulo: USP, 2008.

LEME, Ricardo Carvalho. Expansão urbana e verticalização: o mercado imobiliário de Francisco Beltrão, PR. Tese (Doutorado em Geografia). Florianópolis: UFSC, 2015.

MACEDO, Silvio Soares. São Paulo, paisagem e habitação verticalizada: os espaços livres como elementos do desenho urbano. Tese (Doutorado em Arquitetura e Urbanismo). São Paulo: USP, 1987.

MACHADO, Marcia Maria Magela. Verticalização das cidades: o papel da legislação no caso do bairro Sion em Belo Horizonte. Dissertação (Mestrado em Geografia). Belo Horizonte: UFMG, 1997.

MARTINS, Priscila Celeste. Os "gigantes" na dinâmica urbana de Catalão (GO): a atuação do capital - da especulação à verticalização (1975-2010). Dissertação (Mestrado em Geografia). Catalão: UFG, 2010.

MEDEIROS, Iolanda Aida de. Globalização dos lugares: a verticalização de Manaus. Dissertação (Mestrado em Geografia). São Paulo: USP, 1996.

MELLO, Gisele Homem de. Expansão e estrutura urbana de Santos (SP): aspectos da periferização, da deterioração, da intervenção urbana, da verticalização e da sociabilidade. Dissertação (Mestrado em Sociologia). São Paulo: USP, 2008.

MELO, Yvaldyne Maria Neves de Couto. Considerações sobre os campus públicos e a verticalização como espaço-resposta para a saturação e fragmentação do espaço físico do campus sede da UEM. Dissertação (Mestrado em Geografia). Maringá: UEM, 2001.

MENDES, Cesar Miranda. O edifício no jardim: um plano destruído. A verticalização de Maringá. Tese (Doutorado em Geografia). São Paulo: USP, 1992.

MENDES, César Miranda. Aspectos culturais do consumo e da mercantilização do processo de verticalização do eixo Maringá, Londrina, Arapongas e Apucarana, (PR), Brasil.

MENDES, César Miranda; TOWS, Ricardo Luiz (Orgs.). A Geografia da verticalização urbana em algumas cidades médias no Brasil. Maringá: Eduem, 2009.

MENDONÇA, Eneida Maria Souza. Transferência de interesse no percurso da verticalização de construção em Vitória (ES). Tese (Doutorado em Arquitetura e Urbanismo). São Paulo: USP, 2002. 
MENEZES, Marcia Gois de. A verticalização em Aracaju: surgimento, desenvolvimento e estagnação do processo de verticalização no bairro Centro da capital sergipana (19511991). Dissertação (Mestrado em Arquitetura e Urbanismo). São Paulo: Universidade Presbiteriana Mackenzie, 2008.

MICHELIN, Rodrigo Fernandes. A verticalização da Vila Romana: 1964 à 2012. Dissertação (Mestrado em Arquitetura e Urbanismo). São Paulo: Universidade Presbiteriana Mackenzie, 2012.

NASCIMENTO, Claudinei Ferreira. A verticalização de Londrina-PR: financeirização e mercado imobiliário entre 2000-2013. Dissertação (Mestrado em Geografia). Londrina: UEL, 2015.

NETTO, Isaac da Costa Carvalho. A verticalização na cidade de São José dos Campos, SP, sob a ótica do adensamento: um estudo de caso. Dissertação (Mestrado em Administração). Taubaté: Unitau, 2012.

NOBREGA, Flavia Dantas da. O processo de verticalização e a (re)produção da cidade: um estudo do bairro de Manaíra em João Pessoa, PB. Dissertação (Mestrado em Arquitetura e Urbanismo). João Pessoa: UFPB, 2011.

OKANO, Tais Lie. Verticalização e modernidade: São Paulo (1940-1957). Dissertação (Mestrado em Arquitetura e Urbanismo). São Paulo: Universidade Presbiteriana Mackenzie, 2007.

OLIVEIRA, Janete Marília Gentil Coimbra de. Produção e apropriação do espaço: a verticalização em Belém-PA. Tese (Doutorado em Geografia). São Paulo: USP, 1992.

OURA, Karen Yukie. Verticalização em Londrina, Paraná (1950-2005): a produção do espaço urbano e seu desenvolvimento pelos edifícios verticais. Dissertação (Mestrado em Arquitetura e Urbanismo). São Paulo: Universidade Presbiteriana Mackenzie, 2007.

PASSOS, Viviane Rodrigues de Lima. A verticalização de Londrina (1970-2000): a ação dos promotores imobiliários. Dissertação (Mestrado em Geografia). Londrina: UEL, 2007.

PEREZ, Denis Roberto Castro. Diretrizes solares para o planejamento urbano: o envelope solar como critério para adensamento e verticalização. Tese (Doutorado em Engenharia Civil, Arquitetura e Urbanismo). Campinas: Unicamp, 2013.

PINHEIRO, Mariana de Vasconcelos. Reprodução do capital e metamorfoses espaciais: um estudo da verticalização de Ponta Negra, Natal, RN. Dissertação (Mestrado em Geografia). Natal: UFRN, 2011.

RAMIRES, Julio Cesar de Lima. A verticalização do espaço urbano de Uberlândia: uma análise da produção e do consumo da habitação. Tese (Doutorado em Geografia). São Paulo: USP, 1998a. 
.O processo de verticalização das cidades brasileiras. Boletim de Geografia, Maringá, v.16, n.1, p.97-105, 1998b.

ROCHA, Robson Edgar. A verticalização no Butantã e o avançar de uma nova fronteira. Dissertação (Mestrado em Geografia). São Paulo: USP, 2015.

SANTOS, Cintia Pereira dos. Processo de verticalização em Londrina: novas formas de produção e consumo de imóveis residenciais (2000 a 2010). Dissertação (Mestrado em Geografia). Presidente Prudente: UNESP, 2011.

SANTOS, Edson Marcos dos. Análise do processo de verticalização no espaço urbano de Cascavel/PR entre os anos de 1990-2008. Dissertação (Mestrado em Geografia).

Guarapuava: Unicentro, 2011.

SANTOS, Luiz Eduardo Neves dos. Estratégias do capital na produção do espaço urbano de São Luís: sobre verticalização e desigualdades socioespaciais (2000-2010). Dissertação (Mestrado em Desenvolvimento Socioeconômico). São Luís: UFMA, 2013.

SILVA, Joseli Maria. A verticalização de Guarapuava (PR) e suas representações sociais. Tese (Doutorado em Geografia). Rio de Janeiro: UFRJ, 2002.

SILVA, Luciana Helena da. A verticalização do espaço urbano: o caso do bairro do Prado, Recife, PE. Dissertação (Mestrado em Geografia). Recife: UFPE, 2008.

SILVEIRA, Fabiana de Albuquerque. Impacto da verticalização na qualidade do espaço residencial: um estudo do bairro Tambaú, João Pessoa, PB. Dissertação (Mestrado em Arquitetura e Urbanismo). João Pessoa: UFPB, 2012.

SOMEKH, Nadia. A (des)verticalização de São Paulo. Dissertação (Mestrado em Arquitetura e Urbanismo). São Paulo: USP, 1987.

A cidade vertical e o urbanismo modernizador: São Paulo (1920-1939). Tese

(Doutorado em Arquitetura e Urbanismo). São Paulo: USP, 1994.

SOUZA, Maria Adélia Aparecida de. A identidade da metrópole: a verticalização de São Paulo. Tese (Livre Docência em Geografia). São Paulo: USP, 1989.

1994.

A identidade da metrópole: a verticalização em São Paulo. São Paulo: Hucitec,

SPOSITO, Maria da Encarnação Beltrão. O chão arranha o céu: a lógica da (re)produção monopolista da cidade. Tese (Doutorado em Geografia). São Paulo: USP, 1991.

TONETTI, Emerson Luis. Potencialidades de adensamento populacional por verticalização das edificações e qualidade ambiental urbana no município de Paranaguá, Paraná, Brasil. Tese (Doutorado em Geografia). Curitiba: UFPR, 2011. 
TOWS, Ricardo Luiz. O processo de verticalização de Londrina e de Maringá (PR) Brasil: o Estado e o capital imobiliário na produção do espaço. Dissertação (Mestrado em Geografia). Maringá: UEM, 2010.

; MENDES, Cesar Miranda. O estudo da verticalização urbana como objeto da Geografia: enfoques e perspectivas metodológicas. Anais do I SEURB - I Simpósio de Estudos Urbanos: desenvolvimento regional e dinâmica ambiental, 29 a 31 de agosto de 2011.

TREMARIN, Adriana Rita. Análise do processo de ocupação e verticalização dos setores estruturais Norte e Sul de Curitiba no contexto do planejamento urbano. Dissertação (Mestrado em Geografia). Curitiba: UFPR, 2001.

TUDINI, Odilin Groxiatti. A arborização de acompanhamento viário e a verticalização da Zona 7 de Maringa-PR. Dissertação (Mestrado em Geografia). Maringá: UEM, 2006.

UEDA, Guilherme Shoiti. Verticalização das cidades brasileiras: uma desconstrução do espaço social. Dissertação (Mestrado em Engenharia Urbana). São Carlos: UFSCAR, 2012.

VAZ, Lilian Fessler. Uma história da habitação coletiva na cidade do Rio de Janeiro: estudo da modernidade através da moradia. Tese (Doutorado em Arquitetura e Urbanismo). São Paulo: USP, 1994.

. Modernidade e moradia: habitação coletiva no Rio de Janeiro nos séculos XIX e XX. Rio de Janeiro: Faperj, 7letras, 2002.

ZEMKE, Miriam Margareth. Processo recente de adensamento imobiliário e verticalização em Itapema/SC. Dissertação (Mestrado em Geografia). Florianópolis: UFSC, 2007.

ZICHELLE, Rodrigo. Estudo sobre a verticalização no bairro do Jardim Anália Franco no município de São Paulo: o uso do SIG como análise espacial. Dissertação (Mestrado em Geografia). São Paulo: USP, 2011.

ZUFFO, Élida Regina de Moraes. Pioneiros modernos: verticalização residencial em Higienópolis. Tese (Doutorado em Arquitetura e Urbanismo). São Paulo: Universidade Presbiteriana Mackenzie, 2009.

Recebido em Dezembro de 2016

Aprovado em Maio de 2017

Publicado em Agosto de 2017 